\title{
Singapore General Hospital Experience on Ethnicity and the Incidence of Postoperative Nausea and Vomiting after Elective Orthopaedic Surgeries
}

\author{
Xin Yu Adeline Leong, ${ }^{1}$ Xian Wen Charlene Kwa, ${ }^{1}$ \\ Shu Hui Elizabeth $\mathrm{Ng}^{2}$ and Liang Khai Darren $\mathrm{Koh}^{1,3,4}$ \\ ${ }^{1}$ Department of Anaesthesiology, Singapore General Hospital, Outram Road, Singapore 169608 \\ ${ }^{2}$ NUHS Anaesthesia, National University Hospital, 5 Lower Kent Ridge Road, Singapore 119074 \\ ${ }^{3}$ Yong Loo Lin School of Medicine, National University of Singapore, 21 Lower Kent Ridge Road, Singapore 119077 \\ ${ }^{4}$ Duke-NUS Medical School, 8 College Road, Singapore 169857 \\ Correspondence should be addressed to Xin Yu Adeline Leong; adelineleong@gmail.com
}

Received 4 August 2015; Revised 24 November 2015; Accepted 26 November 2015

Academic Editor: Robert J. Brosnan

Copyright ( 2015 Xin Yu Adeline Leong et al. This is an open access article distributed under the Creative Commons Attribution License, which permits unrestricted use, distribution, and reproduction in any medium, provided the original work is properly cited.

\begin{abstract}
Introduction. We explored how ethnicity affects the risk of postoperative nausea and vomiting (PONV) and established the correlation of suggested risk factors of PONV in the multiethnic population of Singapore. Methods. 785 patients who underwent orthopaedic surgery were recruited. These comprised 619 Chinese (78.9\%), 76 Malay (9.7\%), 68 Indian (8.7\%), and 22 other (2.8\%) cases. The presence of possible risk factors of PONV and nausea and/or vomiting within $24 \mathrm{~h}$ after surgery was studied. Univariate and multivariate logistic regression analyses were performed. Results. The incidence of PONV was 33.2\% (261 patients). There was no statistically significant difference of PONV incidence between Chinese, Malay, and Indian cases (34.6\% versus $34.2 \%$ versus $29.4 \%, p=0.695)$. Indian females younger than 50 years were found to have a higher incidence of vomiting $(p=0.02)$. The significant risk factors for this population include females, use of nitrous oxide, and a history of PONV. Conclusion. In the groups studied, ethnicity is not a significant risk factor for PONV except for young Indian females who have a higher risk of postoperative vomiting. We suggest the selective usage of antiemetic for young Indian females as prophylaxis and avoiding nitrous oxide use in high-risk patients.
\end{abstract}

\section{Introduction}

Postoperative nausea and vomiting (PONV) are the most frequent side effect of anaesthesia with reported incidences of up to $30 \%[1,2]$ and are associated with significant morbidity such as aspiration and wound dehiscence [3]. A multitude of risk factors such as gender, nonsmoker status, history of PONV or motion sickness, and use of postoperative opioids [4] have been suggested and incorporated into risk stratification models for PONV. Ethnicity, on the other hand, has not been thoroughly investigated.

Knowledge of risk factors of PONV enables anaesthesiologists to target the use of prophylactic interventions judiciously for patients who are most at risk of PONV. This will enable the reduction of the cost of managing PONV as the universal use of PONV prophylaxis has not been shown to be cost-effective [5]. In this study, we aim to study the multiethnic population of Singapore and explore the degree to which ethnicity affects the risk of PONV and the correlation of suggested risk factors and incidence of PONV in this population.

\section{Methods}

Upon the Institutional Review Board's approval, Singapore General Hospital's Department of Anaesthesiology's postoperative database during a period of four months from 
September 2009 to January 2010 collected for a prospective study of patient satisfaction scores in elective orthopaedic operations was used for this retrospective study. The study population comprised elective orthopaedic operations that consisted mainly of joint operations (total knee replacement, total hip replacement), spine and shoulder operations. The primary outcome measured was the presence of nausea and/or vomiting within $24 \mathrm{~h}$ after surgery.

This database used standardized questionnaire forms and completion of these forms was performed by the trained anaesthesia medical officers in charge of the patient on postoperative day 1 upon reviewing of the postoperative patients in the ward. The presence and severity of nausea and vomiting episodes (in terms of mild, moderate, and severe nausea and vomiting) were collected within $24 \mathrm{~h}$ after surgery via direct questioning by a standardized format. Data from the forms and the anaesthetic chart was then collected by the team of researchers for the prospective study and keyed in into the database. Further relevant data on intraoperative and postoperative data that were unavailable in the database (e.g., ethnicity, history of PONV, smoking status, and the use of volatile anaesthetics) were collected retrospectively via the anaesthetic charts and medication charts of the patients. Exclusion criteria in this study included emergency surgery, pregnancy, ASA status V, and incomplete case records.

Possible risk factors of PONV were collected:

(i) Patient factors: ethnicity, age, gender, history of PONV, smoking, and ASA status.

(ii) Surgical factors: duration of surgery.

(iii) Anaesthetic factors: type of anaesthesia (general or regional anaesthesia) and the use of prophylactic antiemetics (pre- and intraoperatively), intraoperative opioids, nitrous oxide, and volatile anaesthetics.

Multivariate logistic regression analysis was performed using the SPSS (Statistical Package for the Social Sciences) programme to determine the odds ratio and significance of PONV for each variable. For univariate analysis, differences among the three ethnic groups were compared using the following tests of significance: Kruskal-Wallis tests for differences in medians and $\chi^{2}$ tests for differences in proportions. Subgroup analyses for use of volatile anaesthetics and nitrous oxide were done using patients who underwent general anaesthesia (GA). History of PONV was only analysed amongst patients with prior operations. A $p$ value of $<0.05$ was considered significant.

\section{Results}

A total of 785 patients were included out of 907 patients. One hundred and twenty-two patients were excluded due to either unavailable or incomplete case records in one or more variables collected for the study. The study group comprised 619 Chinese (78.9\%), 76 Malay (9.7\%), 68 Indian (8.7\%), and 22 other $(2.8 \%)$ cases. This is comparable to the national ethnicity census [6] of $74.1 \%$ Chinese, $13.4 \%$ Malay, 9.2\% Indian, and 3.3\% other racial groups. As the breakdown of ethnicity within the group of others is diverse (e.g., includes
Eurasian, Japanese, Filipino cases), we decided to leave out other ethnicity and analyse the incidence of PONV amongst the 3 predominant ethnic groups in Singapore. To increase power for the study and account for the large number difference between the Chinese and Non-Chinese cases, we also further grouped the relatively smaller numbers of Malay and Indian ethnic groups into a Non-Chinese group. As a result, there were 619 Chinese (81.1\%) and 144 Non-Chinese $(18.9 \%)$ cases, respectively.

Across the 3 races, the Chinese group was older (mean age of 58.3 versus 48.8 for Malay and 51.5 for Indian subjects) and had more females and fewer smokers (Table 1).

There were 297 males (38.9\%) and 466 females (61.1\%) amongst the Chinese, Malay, and Indian group. Out of these, $213(27.9 \%)$ underwent regional anaesthesia (RA) and 550 (72.1\%) received general anaesthesia (GA). Of the patients who had GA, 275 (50.0\%) received nitrous oxide and 275 $(50.0 \%)$ did not, and a majority received volatile agents (97.1\%). Amongst all the patients, $13.4 \%$ of patients declared themselves to be smokers and $86.6 \%$ nonsmokers. The median surgical duration was 2-3 hours.

Within 24 hours after surgery, 257 patients experienced nausea and 168 had vomiting. In total, 260 patients (34.1\%) experienced nausea and/or vomiting.

The analysis showed that there was no statistically significant difference in the incidence of PONV amongst Chinese, Malay, or Indian groups (34.6\% versus $34.2 \%$ versus $29.4 \%$, $p=0.695$; adjusted $p=0.849,0.816$, and 0.577 ) (Table 2). Further grouping of Chinese and Non-Chinese cases to increase power of the study also did not show any difference in PONV incidence (34.6\% in Chinese cases versus $31.9 \%$ in Non-Chinese cases, $p=0.549$ ).

As there were significant baseline characteristic differences of age and gender within our study population, subgroup analysis was done with females younger than 50 years of age. The 50-year-old cutoff was based on Apfel's simplified risk scoring [7] for postdischarge nausea and vomiting. Subgroup analysis revealed that amongst females younger than 50 years of age, there is a higher incidence of vomiting in young Indian females compared to the other ethnic groups $(p=0.020)$ (Table 3 ).

In general, females were 2.294 times more at risk of PONV than males $(p=0.000)$. Patients who received nitrous oxide during operation were 2.112 times more at risk of PONV compared to those without $(p=0.000)$. Patients who experienced prior PONV had 1.889 times increased risk of PONV (0.024).

Interestingly, the use of intraoperative antiemetics seems to confer a higher risk of PONV within the study population $(\mathrm{OR}=1.465, p=0.042)$.

Smoking status did not appear to be a significant risk factor for PONV in Singapore (OR $=1.097, p=0.735)$. The choice between GA and RA also did not affect the risk of PONV ( $p=0.977)$. The other variables of age, ASA status, duration of surgery, and use of preoperative antiemetics and volatiles were not significant risk factors for PONV (Table 4).

Within the subgroup analysis of females less than 50 years, nitrous oxide remained a significant risk factor $(\mathrm{OR}=$ $4.553, p=0.033)$ but not a history of PONV ( $p=0.849)$. 
TABLE 1: Comparison of Chinese, Malay, and Indian characteristics of study group.

\begin{tabular}{|c|c|c|c|c|}
\hline & $\begin{array}{l}\text { Chinese } \\
(n=619)\end{array}$ & $\begin{array}{c}\text { Malay } \\
(n=76)\end{array}$ & $\begin{array}{l}\text { Indian } \\
(n=68)\end{array}$ & $p$ values \\
\hline \multicolumn{5}{|l|}{ Patient characteristics } \\
\hline Age, mean (SD), years & $58.3( \pm 15.9)$ & $48.8( \pm 15.8)$ & $51.5( \pm 16.6)$ & 0.000 \\
\hline Females, $\%$ & 63.7 & 53.9 & 45.6 & 0.006 \\
\hline History of PONV, \% & 8.2 & 11.8 & 6.2 & 0.416 \\
\hline Smokers, \% & 11.1 & 26.3 & 19.1 & 0.000 \\
\hline \multicolumn{5}{|l|}{ ASA status, $\%$} \\
\hline I & 20.8 & 28.9 & 20.6 & \multirow{3}{*}{0.108} \\
\hline II & 63.0 & 48.7 & 63.2 & \\
\hline III \& IV & 16.2 & 22.4 & 16.2 & \\
\hline General anaesthesia, \% & 71.1 & 72.4 & 80.9 & 0.231 \\
\hline Received preoperative antiemetics, $\%$ & 7.9 & 9.2 & 8.8 & 0.905 \\
\hline Received intraoperative antiemetics, \% & 37.2 & 44.7 & 48.5 & 0.104 \\
\hline Received opioids, \% & 90.0 & 85.5 & 91.2 & 0.441 \\
\hline \multicolumn{5}{|l|}{ Anaesthetic } \\
\hline Nitrous oxide use, \% & 34.2 & 46.1 & 41.2 & 0.084 \\
\hline Use of volatile agents, $\%$ & 68.8 & 69.7 & 80.9 & 0.120 \\
\hline \multicolumn{5}{|l|}{ Surgical } \\
\hline \multicolumn{5}{|l|}{ Duration of surgery, \% } \\
\hline$<3 \mathrm{~h}$ & 76.3 & 80.3 & 77.9 & \multirow{4}{*}{0.701} \\
\hline 3 to $<4 \mathrm{~h}$ & 15.7 & 11.8 & 19.1 & \\
\hline 4 to $<5 \mathrm{~h}$ & 7.8 & 7.9 & 2.9 & \\
\hline $5 \mathrm{~h}$ and more & 0.3 & 0.0 & 0.0 & \\
\hline
\end{tabular}

TABLE 2: Incidence of nausea, vomiting, and nausea and/or vomiting amongst ethnic groups.

\begin{tabular}{|c|c|c|c|c|}
\hline & $\begin{array}{c}\text { Chinese } \\
(n=619)\end{array}$ & $\begin{array}{c}\text { Malay } \\
(n=76)\end{array}$ & $\begin{array}{c}\text { Indian } \\
(n=68) \\
\end{array}$ & $p$ values \\
\hline Nausea (total), \% & 34.3 & 32.9 & 29.4 & 0.717 \\
\hline Mild & 29.1 & 30.3 & 23.5 & \multirow{3}{*}{0.868} \\
\hline Moderate & 3.6 & 2.6 & 4.4 & \\
\hline Severe & 1.6 & 0.0 & 1.5 & \\
\hline Vomiting (total), \% & 22.8 & 17.1 & 20.6 & 0.507 \\
\hline Mild & 17.0 & 14.5 & 13.2 & \multirow{3}{*}{0.825} \\
\hline Moderate & 4.8 & 2.6 & 5.9 & \\
\hline Severe & 1.0 & 0.0 & 1.5 & \\
\hline \multirow[t]{2}{*}{ Nausea and/or vomiting, \% } & 34.6 & 34.2 & 29.4 & 0.695 \\
\hline & $\begin{array}{c}\text { Chinese } \\
(n=619)\end{array}$ & \multicolumn{2}{|r|}{$\begin{array}{l}\text { Non-Chinese } \\
(n=144)\end{array}$} & $p$ value \\
\hline Nausea (total), \% & 34.2 & \multicolumn{2}{|r|}{31.2} & 0.493 \\
\hline Mild & 29.1 & \multicolumn{2}{|r|}{27.1} & \\
\hline Moderate & 3.6 & \multicolumn{2}{|r|}{3.5} & 0.799 \\
\hline Severe & 1.6 & \multicolumn{2}{|r|}{0.7} & \\
\hline Vomiting (total), \% & 22.8 & \multicolumn{2}{|r|}{18.8} & 0.293 \\
\hline Mild & 17 & \multicolumn{2}{|r|}{13.9} & \\
\hline Moderate & 4.8 & \multicolumn{2}{|r|}{4.2} & 0.770 \\
\hline Severe & 1.0 & \multicolumn{2}{|r|}{0.7} & \\
\hline Nausea and/or vomiting, $\%$ & 34.6 & \multicolumn{2}{|r|}{31.9} & 0.549 \\
\hline
\end{tabular}


TABLE 3: Incidence of nausea, vomiting, and nausea and/or vomiting amongst females $<50$ years.

\begin{tabular}{|c|c|c|c|c|}
\hline & $\begin{array}{l}\text { Chinese } \\
(n=61)\end{array}$ & $\begin{array}{c}\text { Malay } \\
(n=14)\end{array}$ & $\begin{array}{l}\text { Indian } \\
(n=10)\end{array}$ & $p$ values \\
\hline Nausea (total), \% & 37.7 & 50.0 & 50.0 & 0.584 \\
\hline Mild & 29.5 & 42.9 & 40.0 & \multirow{3}{*}{0.563} \\
\hline Moderate & 6.6 & 7.1 & 0.0 & \\
\hline Severe & 1.6 & 0.0 & 10.0 & \\
\hline Vomiting (total), \% & 2.62 & 7.1 & 50.0 & 0.061 \\
\hline Mild & 18.0 & 0.0 & 40.0 & \multirow{3}{*}{0.020} \\
\hline Moderate & 8.2 & 7.1 & 0.0 & \\
\hline Severe & 0.0 & 0.0 & 10.0 & \\
\hline Nausea and/or vomiting, \% & 37.7 & 50.0 & 50.0 & 0.584 \\
\hline
\end{tabular}

TABLE 4: Multivariate analysis of PONV variables.

\begin{tabular}{|c|c|c|c|c|}
\hline \multirow{2}{*}{ Patients characteristics } & \multirow[t]{2}{*}{ OR } & \multicolumn{2}{|c|}{$95 \%$ confidence interval } & \multirow[t]{2}{*}{$p$ value } \\
\hline & & & & \\
\hline Age & 1.000 & 0.987 & 1.013 & 0.999 \\
\hline \multicolumn{5}{|l|}{ Ethnicity } \\
\hline Chinese & \multicolumn{3}{|c|}{ As reference } & 0.849 \\
\hline Malay & 1.066 & 0.622 & 1.827 & 0.816 \\
\hline Indian & 1.180 & 0.660 & 2.108 & 0.577 \\
\hline Females & 2.294 & 1.590 & 3.311 & 0.000 \\
\hline History of PONV* & 1.889 & 1.088 & 3.277 & 0.024 \\
\hline Smokers & 1.097 & 0.641 & 1.878 & 0.735 \\
\hline \multicolumn{5}{|l|}{ ASA status } \\
\hline ASA 1 & \multicolumn{3}{|c|}{ As reference } & 0.928 \\
\hline ASA 2 & 1.003 & 0.642 & 1.567 & 0.989 \\
\hline ASA 3 & 1.170 & 0.647 & 2.115 & 0.603 \\
\hline ASA 4 & 0.959 & 0.055 & 16.644 & 0.977 \\
\hline General anaesthesia & 1.018 & 0.315 & 3.286 & 0.977 \\
\hline Received preoperative antiemetics & 0.727 & 0.392 & 1.347 & 0.310 \\
\hline Received intraoperative antiemetics & 1.465 & 1.014 & 2.118 & 0.042 \\
\hline Received opioids & 0.922 & 0.521 & 1.630 & 0.779 \\
\hline \multicolumn{5}{|l|}{ Anaesthetic ${ }^{* *}$} \\
\hline Nitrous oxide use & 2.112 & 1.419 & 3.145 & 0.000 \\
\hline Use of volatile agents & 0.661 & 0.213 & 2.046 & 0.472 \\
\hline \multicolumn{5}{|l|}{ Surgical } \\
\hline \multicolumn{5}{|l|}{ Duration of surgery } \\
\hline$\leq 3 \mathrm{~h}$ & \multicolumn{3}{|c|}{ As reference } & 0.742 \\
\hline$>3$ to $\leq 4 \mathrm{~h}$ & 0.904 & 0.585 & 1.397 & 0.650 \\
\hline$>4$ to $\leq 5 \mathrm{~h}$ & 1.250 & 0.657 & 2.376 & 0.496 \\
\hline$>5 \mathrm{~h}$ & 0.363 & 0.021 & 6.411 & 0.489 \\
\hline \multicolumn{5}{|c|}{ The Chinese compared to the Non-Chinese ${ }^{* * *}$} \\
\hline Chinese & 1.117 & 0.735 & 1.697 & 0.604 \\
\hline
\end{tabular}

${ }^{*}$ History of PONV subanalysed amongst patients who had previous operations.

** Anaesthetic variables subanalysed amongst patients who underwent General Anaesthesia.

${ }^{* * *}$ The data is the odds ratio of the Chinese compared to the Non-Chinese in incidence of PONV. 
TABLE 5: Multivariate analysis of PONV variables in subgroup of females $<50$ years.

\begin{tabular}{|c|c|c|c|c|}
\hline & OR & \multicolumn{2}{|c|}{ 95\% confidence interval } & $p$ value \\
\hline \multicolumn{4}{|l|}{ Patients characteristics } & \\
\hline Age & 0.952 & 0.889 & 1.019 & 0.153 \\
\hline \multicolumn{5}{|l|}{ Ethnicity } \\
\hline Chinese & \multicolumn{3}{|c|}{ As reference } & 0.330 \\
\hline Malay & 0.312 & 0.045 & 2.150 & 0.237 \\
\hline Indian & 0.352 & 0.056 & 2.204 & 0.265 \\
\hline History of PONV* & 1.242 & 0.134 & 11.542 & 0.849 \\
\hline Smokers & 2.856 & 0.486 & 16.768 & 0.245 \\
\hline \multicolumn{5}{|l|}{ ASA status } \\
\hline ASA 1 & \multicolumn{3}{|c|}{ As reference } & 0.114 \\
\hline ASA 2 & 0.777 & 0.222 & 2.724 & 0.693 \\
\hline ASA 3 & 27.257 & 0.975 & 756.162 & 0.052 \\
\hline ASA 4 & None & & & \\
\hline Received preoperative antiemetics & 17.269 & 1.195 & 249.504 & 0.037 \\
\hline Received intraoperative antiemetics & 0.275 & 0.076 & 0.997 & 0.049 \\
\hline \multicolumn{5}{|l|}{ Anaesthetic $^{* *}$} \\
\hline Nitrous oxide use & 4.553 & 1.132 & 18.311 & 0.033 \\
\hline Use of volatile agents & 0.663 & 0.043 & 10.193 & 0.768 \\
\hline \multicolumn{5}{|l|}{ Surgical } \\
\hline \multicolumn{5}{|l|}{ Duration of surgery } \\
\hline$\leq 3 \mathrm{~h}$ & \multicolumn{3}{|c|}{ As reference } & 0.568 \\
\hline$>3$ to $\leq 4 \mathrm{~h}$ & 0.470 & 0.084 & 2.622 & 0.389 \\
\hline$>4$ to $\leq 5 \mathrm{~h}$ & 0.384 & 0.036 & 4.054 & 0.426 \\
\hline \multicolumn{5}{|c|}{ The Chinese compared to the Non-Chinese ${ }^{* * *}$} \\
\hline Chinese & 0.332 & 0.078 & 1.418 & 0.137 \\
\hline
\end{tabular}

${ }^{*}$ History of PONV subanalysed amongst patients who had previous operations.

${ }^{* *}$ Anaesthetic variables subanalysed amongst patients who underwent general anaesthesia.

${ }^{* * *}$ The data is the odds ratio of the Chinese compared to the Non-Chinese in incidence of PONV.

Note: GA and intraoperative opioids not included in table as almost all within the group had received GA and intraoperative opioids.

Intraoperative antiemetic use within this group conferred a lower risk of PONV $(\mathrm{OR}=0.275, p=0.049)$ (Table 5).

\section{Discussion}

Ethnicity has been proposed as a risk factor for PONV, and results have been contentious. In 2010, Rodseth et al. concluded from a study done in South Africa comprising 800 subjects that there is a statistically significant reduced incidence of PONV in black South Africans as compared to the rest of the multiethnic South Africans [8]. A metaanalysis of PONV after gynaecological surgery also suggests that ethnicity could be a PONV risk factor [9]. In contrast, Toner et al's study of 400 subjects in London revealed no difference in the risk of PONV in different ethnicities [10].

Our findings showed that the risk of PONV in general is not significant amongst the Chinese, Malays, and Indians. However, young Indian females seem to be at particular risk for postoperative vomiting.

It has been suggested that ethnicity is a risk factor for PONV due to the differential degree of expression and activity of selected cytochrome P (CYP) 450 isoenzymes [11], which affects metabolism of many used anaesthetic and analgesic drugs responsible for PONV $[2,12]$. This is suggested in Sweeney's hypothesis that the protective effect of smoking against PONV may be the result of induction of CYP1A2 enzymes by polycyclic aromatic hydrocarbons [13]. It has been shown that the CYP1A2* $1 \mathrm{D}$ allele, which is associated with increased CYP1A2 enzymatic activity, [14] has a higher frequency in the Chinese and Malays than the Indians [15]. This suggests that Indians are slower metabolizers which may predispose them to have higher PONV risks.

The difference in risk also results from a dynamic threshold for nausea which depends on the interaction of inherent factors and more changeable psychological factors [11]. Inherent factors described include age, gender, and race, whilst psychological factors include anxiety, expectation, anticipation, and adaptation.

Indeed, our finding of young Indian females having increased risk of postoperative vomiting may be associated with the increased pain perception and requirements of opioids. Both pain and opioid use are known to have 
effect on nausea and vomiting. As demonstrated in young Indian females undergoing Lower Segment Caesarean Section (LSCS) in Singapore, these patients have significantly higher pain scores and opioid usage [16].

Consistent with the findings of major studies such as Apfel [4] and Koivuranta, [17] female gender has been shown to be a strong risk factor with a relative risk of 2.294 times of developing PONV in this study. This is consistent with the two- to fourfold increased risk of PONV as reported in most studies [2]. Likewise, history of PONV was also shown to be a strong risk factor of PONV in this study. The nonsignificant risk finding of PONV within the subgroup of females younger than 50 years of age is likely attributed to small numbers of patients who had previous operations at a young age, and subgroup analysis of PONV risk within this subgroup lacks adequate power (as also evidenced by the widened confidence interval) (Table 5).

While smoking is reported to reduce risk of PONV [13, $18,19]$, there have also been some contradictory reports by Toner et al. [10] and Pierre et al. [20]. In Singapore, smoking status did not seem to make a significant difference in the risk of PONV. Smoking rate in our study (13.6\%) was similar to a reported prevalence of $14.5 \%$ within Singapore in the year 2010 [21].

Amongst the various anaesthesia-related risk factors for PONV, in particular we have found that the use of nitrous oxide greatly increases the risk of PONV by 2.112 times ( $95 \%$ CI 1.419 to 3.145). This is consistent with our subgroup of young females $(\mathrm{OR}=4.553, p=0.033)$ and the results of various studies including a meta-analysis [22] which found that avoidance of nitrous oxide decreases the incidence of PONV. It is proposed that nitrous oxide influences the vestibular system by diffusing into the closed cavity of the middle ear, expansion of the intestinal wall, or releases endogenous opioid peptides which activate the area postrema of the brain [23]. We believe that avoidance of nitrous oxide use especially in high-risk patients would reduce the risk of PONV.

An interesting finding was the lack of significant increase in PONV for RA compared to GA in our study. Given our population who underwent orthopaedic operations that generally included total knee replacements and hip operations, a majority of RA would include central neuraxial blocks with or without opioid inclusion. This is different from Sinclair et al.s study [24] which showed that GA increased risk of PONV 11 times compared to RA. However, the study included various forms of RA such as local anaesthesia, monitored anaesthetic care, and central and peripheral regional blockade: this may result in the different findings between our study population and theirs. It is possible that the inclusion of opioids in central neuraxial blockade and hypotension postneuraxial blockade as well as the use of intra-articular opioids by the surgeons has caused in an increased risk in PONV in RA in our population, resulting in no difference in PONV risk between RA and GA. Unfortunately, we do not have data on inclusion of opioids in central neuraxial blocks, intra-articular opioids, or incidence of hypotension after RA or GA to further analyse the data for any conclusion.
We did not have sufficient data regarding use of postoperative opioids or postoperative antiemetics which may confound the results of the severity of PONV. Further studies such as a prospective study controlling for these factors as well as the other anaesthetic factors and having greater numbers of the Indians and Malays would provide a clearer understanding on the exact extent of increased PONV risk in young Indian females.

\section{Conclusion}

Young Indian females have a higher risk of postoperative vomiting, and no other effect of ethnicity on PONV risk could be detected for those groups included in the present preliminary study. We suggest the selective usage of antiemetic for young Indian females as prophylaxis and avoiding nitrous oxide use in high-risk patients.

\section{Conflict of Interests}

The authors declare that there is no conflict of interests regarding the publication of this paper.

\section{Acknowledgments}

The authors would like to thank Ms. Ma Thin Mar Win (Department of Anaesthesiology, Singapore General Hospital) and A/Professor Lee Chun Fan (Biostatician, Singapore Clinical Research Institute) for their invaluable assistance and advice in data analysis, as well as the SGH's Department of Anaesthesiology for providing them with the patients' database.

\section{References}

[1] L. H. J. Eberhart, J. Högel, W. Seeling, A. M. Staack, G. Geldner, and M. Georgieff, "Evaluation of three risk scores to predict postoperative nausea and vomiting," Acta Anaesthesiologica Scandinavica, vol. 44, no. 4, pp. 480-488, 2000.

[2] T. J. Gan, "Risk factors for postoperative nausea and vomiting," Anesthesia and Analgesia, vol. 102, no. 6, pp. 1884-1898, 2006.

[3] C. C. Apfel, P. Kranke, M. H. Katz et al., "Volatile anaesthetics may be the main cause of early but not delayed postoperative vomiting: a randomized controlled trial of factorial design," British Journal of Anaesthesia, vol. 88, no. 5, pp. 659-668, 2002.

[4] C. C. Apfel, E. Läärä, M. Koivuranta, C.-A. Greim, and N. Roewer, "A simplified risk score for predicting postoperative nausea and vomiting: conclusions from cross-validations between two centers," Anesthesiology, vol. 91, no. 3, pp. 693-700, 1999.

[5] A. S. Habib and T. J. Gan, "Evidence-based management of postoperative nausea and vomiting: a review," Canadian Journal of Anesthesia, vol. 51, no. 4, pp. 326-341, 2004.

[6] Department of Statistics, Ministry of Trade \& Industry, and Republic of Singapore, Census of Population 2010 Statistical Release 1: Demographic Characteristics, Education, Language and Religion, Department of Statistics, Ministry of Trade \& Industry, Republic of Singapore, 2010. 
[7] C. C. Apfel, B. K. Philip, O. S. Cakmakkaya et al., "Who is at risk for postdischarge nausea and vomiting after ambulatory surgery?” Anesthesiology, vol. 117, no. 3, pp. 475-486, 2012.

[8] R. N. Rodseth, P. D. Gopalan, H. M. Cassimjee, and S. Goga, "Reduced incidence of postoperative nausea and vomiting in black South Africans and its utility for a modified risk scoring system," Anesthesia and Analgesia, vol. 110, no. 6, pp. 1591-1594, 2010.

[9] C. G. Haigh, L. A. Kaplan, J. M. Durham, J. P. Dupeyron, M. Harmer, and G. N. C. Kenny, "Nausea and vomiting after gynaecological surgery: a meta-analysis of factors affecting their incidence," British Journal of Anaesthesia, vol. 71, no. 4, pp. 517$522,1993$.

[10] C. C. Toner, C. J. Broomhead, I. H. Littlejohn et al., "Prediction of postoperative nausea and vomiting using a logistic regression model," British Journal of Anaesthesia, vol. 76, no. 3, pp. 347-351, 1996.

[11] R. M. Stern, “The psychophysiology of nausea," Acta Biologica Hungarica, vol. 53, no. 4, pp. 589-599, 2002.

[12] K. A. Candiotti, D. J. Birnbach, D. A. Lubarsky et al., "The impact of pharmacogenomics on postoperative nausea and vomiting: do CYP2D6 allele copy number and polymorphisms affect the success or failure of ondansetron prophylaxis?" Anesthesiology, vol. 102, no. 3, pp. 543-549, 2005.

[13] B. P. Sweeney, "Why does smoking protect against PONV?" British Journal of Anaesthesia, vol. 89, no. 6, pp. 810-813, 2002.

[14] S. Pavanello, A. Pulliero, S. Lupi, P. Gregorio, and E. Clonfero, "Influence of the genetic polymorphism in the $5^{\prime}$-noncoding region of the CYP1A2 gene on CYP1A2 phenotype and urinary mutagenicity in smokers," Mutation Research, vol. 587, no. 1-2, pp. 59-66, 2005.

[15] D. K. Badyal and A. P. Dadhich, "Cytochrome P450 and drug interactions," Indian Journal of Pharmacology, vol. 33, no. 4, pp. 248-259, 2001.

[16] E.-C. Tan, Y. Lim, Y.-Y. Teo, R. Goh, H.-Y. Law, and A. T. Sia, "Ethnic differences in pain perception and patient-controlled analgesia usage for postoperative pain," Journal of Pain, vol. 9, no. 9, pp. 849-855, 2008.

[17] M. Koivuranta, E. Läärä, L. Snåre, and S. Alahuhta, "A survey of postoperative nausea and vomiting," Anaesthesia, vol. 52, no. 5, pp. 443-449, 1997.

[18] R. Morino, M. Ozaki, O. Nagata, and M. Yokota, "Incidence of and risk factors for postoperative nausea and vomiting at a Japanese Cancer Center: first large-scale study in Japan," Journal of Anesthesia, vol. 27, no. 1, pp. 18-24, 2013.

[19] W. Chimbira and B. P. Sweeney, "The effect of smoking on postoperative nausea and vomiting," Anaesthesia, vol. 55, no. 6, pp. 540-544, 2000.

[20] S. Pierre, H. Benais, and J. Pouymayou, "Apfel's simplified score may favourably predict the risk of postoperative nausea and vomiting," Canadian Journal of Anesthesia, vol. 49, no. 3, pp. 237-242, 2002.

[21] Singapore Burden of Diseases Study, MOHH, December 2013, http://www.moh.gov.sg/content/moh_web/home/statistics/Health _Facts_Singapore/Disease_Burden.html.

[22] J. Fernández-Guisasola, J. I. Gómez-Arnau, Y. Cabrera, and S. G. Del Valle, "Association between nitrous oxide and the incidence of postoperative nausea and vomiting in adults: a systematic review and meta-analysis: review article," Anaesthesia, vol. 65, no. 4 , pp. 379-387, 2010.
[23] M. E. Kreis, "Postoperative nausea and vomiting," Autonomic Neuroscience: Basic and Clinical, vol. 129, no. 1-2, pp. 86-91, 2006.

[24] D. R. Sinclair, F. Chung, and G. Mezei, "Can postoperative nausea and vomiting be predicted?" Anesthesiology, vol. 91, no. 1, pp. 109-118, 1999 


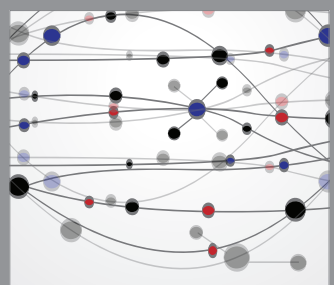

The Scientific World Journal
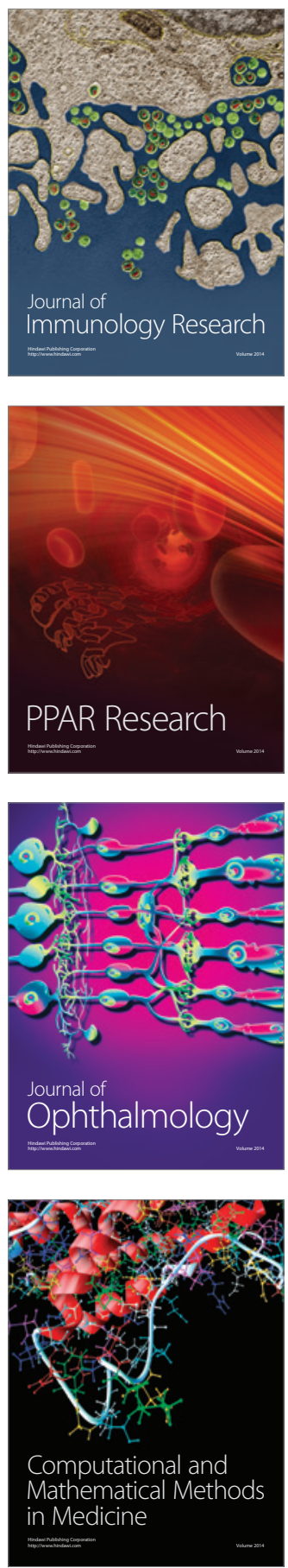

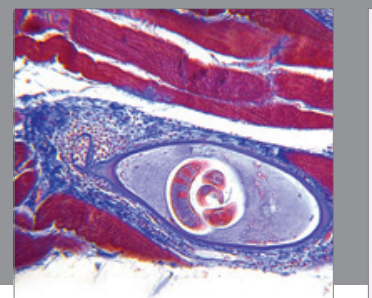

Gastroenterology

Research and Practice
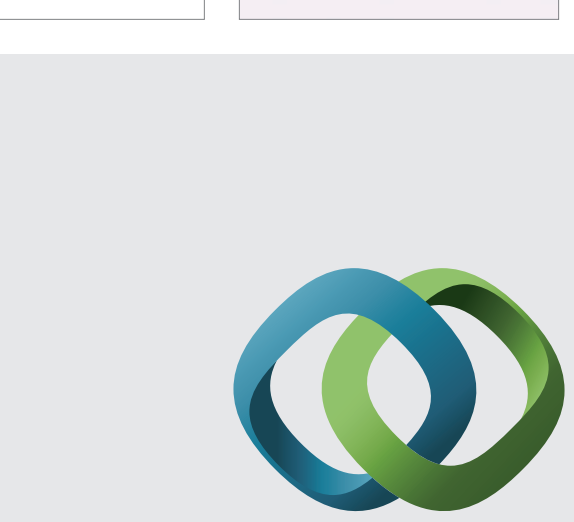

\section{Hindawi}

Submit your manuscripts at

http://www.hindawi.com
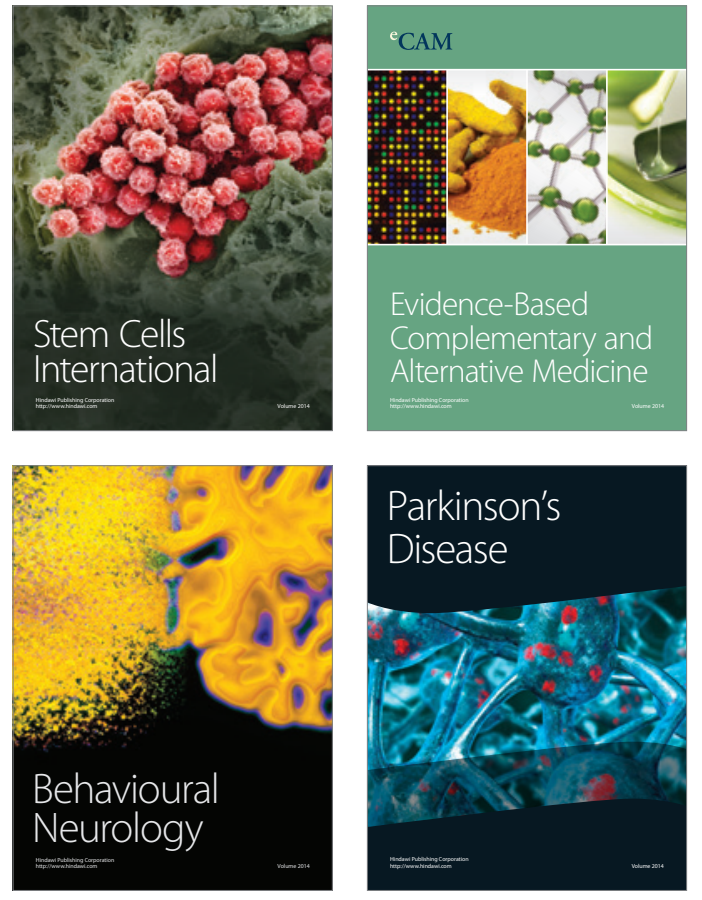
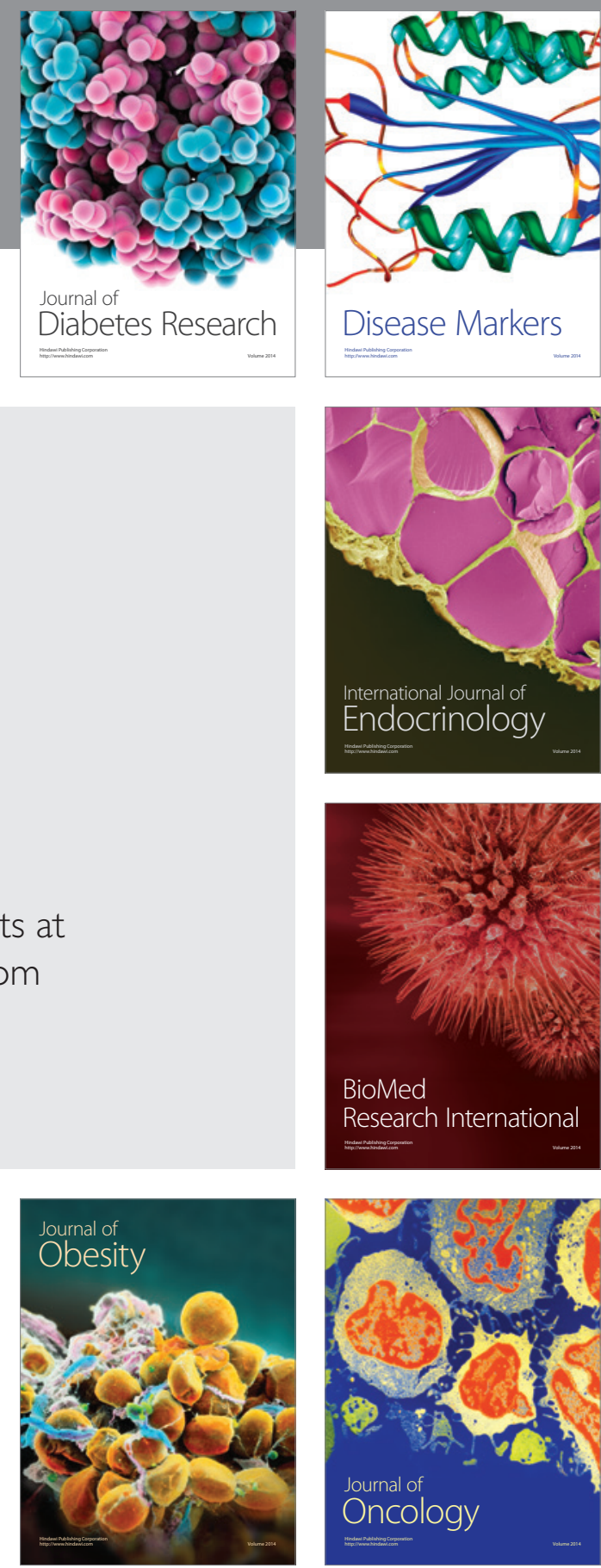

Disease Markers
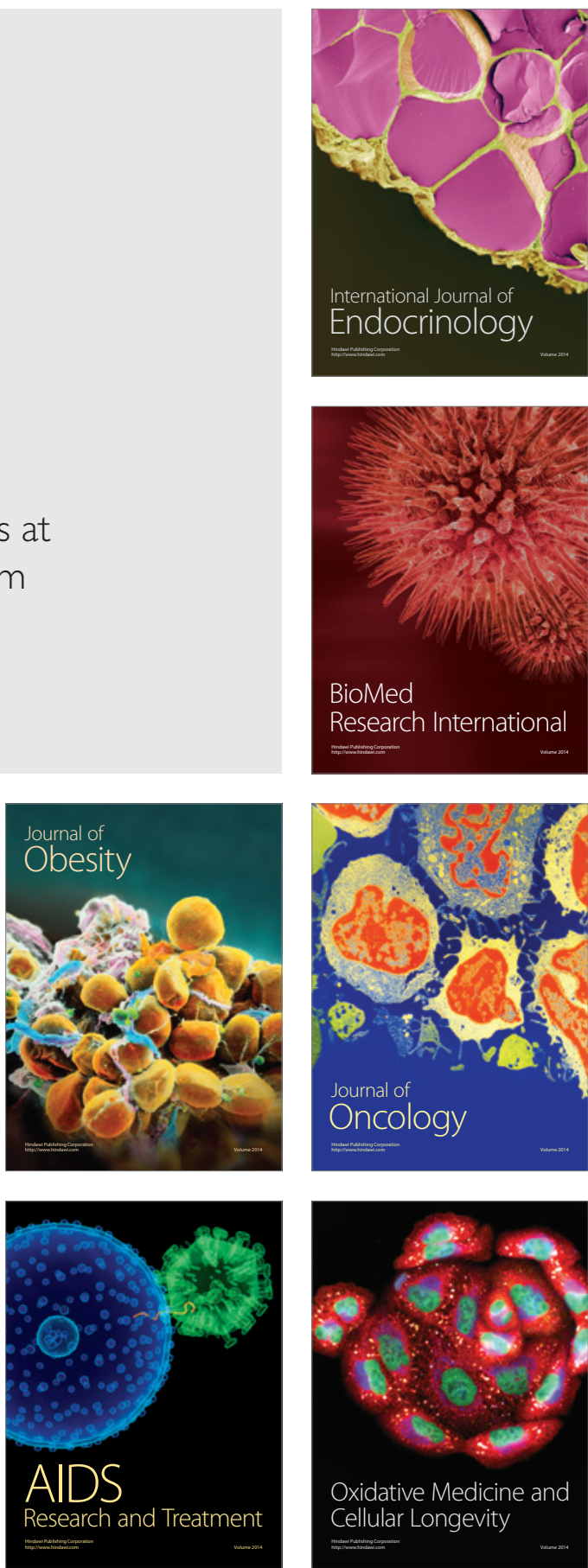